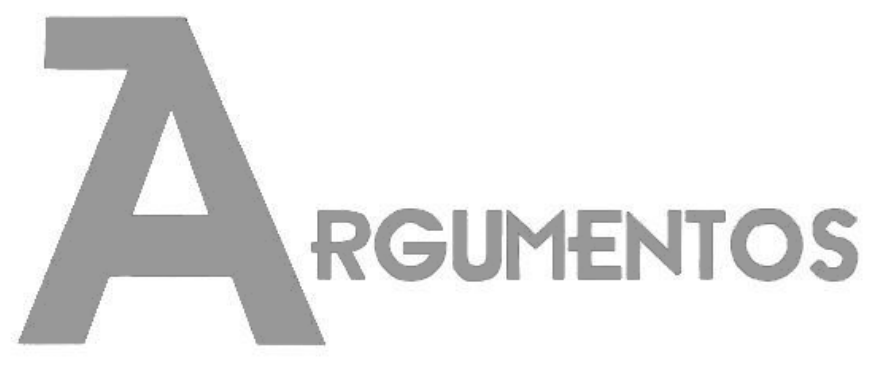

Vol. 17, n. 2, jul./dez. 2020 ISSN: 2527-2551 (online)

https://www.periodicos.unimontes.br/index.php/argumentos

\title{
A iniciação esportiva no esporte paralímpico: o caso do voleibol sentado
}

\author{
Vitória Crivellaro Sanchotene ${ }^{1}$ \\ Giandra Anceski Bataglion² \\ Janice Zarpellon Mazo ${ }^{3}$
}

Recebido em: 08/04/2020

Aprovado em: 01/06/2020

Resumo: Este estudo tem como objetivo averiguar como ocorreu a inserção de atletas da seleção brasileira feminina de voleibol sentado na prática esportiva paralímpica. Para tanto, a coleta de dados foi realizada por meio de entrevistas semiestruturadas com cinco atletas que participaram dos Jogos Paralímpicos nas edições de 2012, em Londres, e de 2016, no Rio de Janeiro. Evidenciou-se que a inserção das atletas na prática do voleibol sentado foi intermediada por indicações de profissionais da área da saúde e do esporte, com destaque para os treinadores da modalidade, que desempenharam papel proeminente no processo de iniciação destas atletas no esporte paralímpico. A Educação Física escolar despontou nas falas das atletas como potencial facilitador para o processo de iniciação esportiva, sobretudo, às pessoas com deficiência adquirida na vida adulta. Para tanto, foi ressaltada a necessidade de que as experiências com o esporte na fase escolar sejam positivas, estimulando a permanência na prática da(s) modalidade(s) ao longo da vida e contribuindo para o bem-estar físico e psicossocial da pessoa com deficiência. Os resultados do estudo denotaram que as formas de

\footnotetext{
${ }^{1}$ Doutoranda e Mestra em Ciências do Movimento Humano pela Universidade Federal do Rio Grande do Sul (UFRGS). Integrante do grupo de pesquisa Núcleo de Estudos em História e Memória do Esporte e da Educação Física (NEHME) da UFRGS/CNPq, do Observatório do Esporte Paralímpico/UFRGS e do Centro de Memória do Esporte (CEME/UFRGS). ORCID: https://orcid.org/0000-0001-9731-5890.

2 Doutoranda em Ciências do Movimento Humano pela Universidade Federal do Rio Grande do Sul (UFRGS). Mestra em Educação Física pela Universidade Federal de Santa Catarina (UFSC). Integrante do Núcleo de Estudos em História e Memória do Esporte e da Educação Física (NEHME) da UFRGS/CNPq, do Observatório do Esporte Paralímpico/UFRGS e do Centro de Memória do Esporte (CEME/UFRGS). ORCID: https://orcid.org/0000-0001-8913-9874.

${ }^{3}$ Pós-doutorado em História (IFCH/UFRGS). Doutora em Ciências do Desporto pela Universidade do Porto (Portugal). Professora da Escola de Educação Física, Fisioterapia e Dança da UFRGS. Professora do Programa de Pós-graduação em Ciências do Movimento Humano - Mestrado e Doutorado da UFRGS. Líder do grupo de pesquisa Núcleo de Estudos em História e Memória do Esporte e da Educação Física (NEHME) da UFRGS/CNPq. Coordenadora do Observatório do Esporte Paralímpico/UFRGS e do Centro de Memória do Esporte (CEME/UFRGS). ORCID: https://orcid.org/0000-0002-8215-0058.
} 
Dossiê | A iniciação esportiva no esporte paralímpico: o caso do voleibol sentado (SANCHOTENE, Vitória Crivellaro; BATAGLION, Giandra Anceski; MAZO, Janice Zarpellon)

inserção das mulheres no voleibol sentado no Brasil possuem relações com características que marcaram os primórdios da composição da modalidade no país.

Palavras-chave: Pessoa com Deficiência; Jogos Paralímpicos; Atletas; Mulheres no esporte; Educação Física inclusiva.

\section{Iniciación deportiva en el deporte paralímpico: el caso del voleibol sentado}

Resumen: Este estudio tiene como objetivo investigar cómo se realizó la inserción de atletas del equipo de voleibol femenino brasileño en los deportes paralímpicos. Con este fin, la recopilación de datos se realizó a través de entrevistas semiestructuradas con cinco atletas que participaron en los Juegos Paralímpicos en las ediciones de 2012, en Londres y 2016, en Río de Janeiro. Era evidente que la inserción de atletas en la práctica del voleibol sentado estaba mediada por indicaciones de profesionales de la salud y el deporte, con énfasis en los entrenadores del deporte, que desempeñaron un papel destacado en el proceso de iniciación de estos atletas en el deporte paralímpico. La Educación Física Escolar surgió en los discursos de los atletas como un posible facilitador para el proceso de iniciación deportiva, especialmente para personas con discapacidades adquiridas en la edad adulta. Por lo tanto, se enfatizó la necesidad de que las experiencias con el deporte en la fase escolar sean positivas, fomentando la permanencia en la práctica de las modalidades a lo largo de la vida y contribuyendo al bienestar físico y psicosocial de la persona con discapacidad Los resultados del estudio mostraron que las formas de inserción de las mujeres en el voleibol sentado en Brasil tienen relaciones con características que marcaron los inicios de la composición del deporte en el país.

Palabras clave: Persona discapacitada; Juegos Paralímpicos; Atletas Mujeres en el deporte; Educación física inclusiva.

\section{Sports initiation in paralympic sport: the case of sitting volleyball}

Abstract: This study aims to investigate how the insertion of athletes from the Brazilian women's volleyball team took place in Paralympic sports. To this end, data collection was carried out through semi-structured interviews with five athletes who participated in the Paralympic Games in the 2012 editions, in London, and 2016, in Rio de Janeiro. It was evident that the insertion of athletes in the practice of seated volleyball was mediated by indications from health and sport professionals, with emphasis on the coaches of the sport, who played a prominent role in the initiation process of these athletes in Paralympic sport. School Physical Education emerged in the athletes' speeches as a potential facilitator for the sport initiation process, especially for people with disabilities acquired in adulthood. Therefore, the need was emphasized that the experiences with sport in the school phase are positive, encouraging the permanence in the practice of the modality (s) throughout life and contributing to the physical and psychosocial well-being of the person with deficiency. The results of the study showed that the forms of insertion of women in sitting volleyball in Brazil have relationships with characteristics that marked the beginnings of the composition of the sport in the country.

Keywords: Disabled Person; Paralympic Games; Athletes; Women in sport; Inclusive Physical Education.

\section{Introdução}

Este estudo versa sobre o processo de iniciação esportiva de atletas da seleção brasileira feminina de voleibol sentado. De acordo com Carvalho, Gorla e Araújo (2013) e Conde (2018), a difusão desta modalidade paralímpica, em sua forma 
Dossiê | A iniciação esportiva no esporte paralímpico: o caso do voleibol sentado (SANCHOTENE, Vitória Crivellaro; BATAGLION, Giandra Anceski; MAZO, Janice Zarpellon)

institucionalizada, ocorreu no Brasil a partir da década de 2000. Portanto, no país, a iniciação esportiva no voleibol sentado, tanto pelas mulheres como pelos homens, pode ser compreendida como recente, se tratando de menos de duas décadas da modalidade no país (SANCHOTENE, 2019). Neste cenário, em Jogos Paralímpicos, o voleibol sentado brasileiro teve seleção feminina representante pela primeira vez na edição de 2012, em Londres (Inglaterra), e; posteriormente, em 2016, no Rio de Janeiro (Brasil) (VICCARI; MATTES, 2018).

Os Jogos Paralímpicos se constituem no maior evento esportivo mundial de esportes paralímpicos - este, considerado a forma institucionalizada do esporte de alto rendimento para pessoas com deficiência. Neste sentido, cabe referir que pessoa com deficiência é "aquela que tem impedimento de longo prazo de natureza física, mental, intelectual ou sensorial, o qual, em interação com uma ou mais barreiras, pode obstruir sua participação plena e efetiva na sociedade em igualdade de condições com as demais pessoas" (BRASIL, 2011).

De acordo com o último Censo do Instituto Brasileiro de Geografia e Estatística (IBGE, 2010), no item "População residente por tipo de deficiência permanente", o total de 13.265.599 pessoas indicaram possuir diagnóstico de algum tipo de deficiência física, a qual é denominada pelo IBGE de deficiência motora. Leis e diretrizes contribuem para a busca por igualdade de condições e de oportunidades da pessoa com deficiência na sociedade (REIS; MEZZADRI; SILVA, 2017). Assim como a educação, a saúde, o trabalho e o lazer, o esporte é direito da pessoa com deficiência (BRASIL, 2015). Apesar disto estar garantido em dispositivos legais, como na Lei Brasileira de Inclusão da Pessoa com Deficiência (LDB) (Estatuto da Pessoa com Deficiência), de 2015 (BRASIL, 2015), sabe-se que o acesso à prática esportiva é dificultado à essa população devido a variadas barreiras - arquitetônicas, atitudinais, sociais, dentre outras.

A prática esportiva se constitui em um espaço de oportunidades e empoderamento para as pessoas com deficiência - em especial, no caso das mulheres -, podendo gerar crescimento pessoal e contribuir para a promoção da saúde, o sentimento de pertencimento, o estabelecimento de objetivos, dentre outros benefícios. Para tal, incentiva-se maiores espaços para a prática deste público, pois ambientes que possibilitam a prática esportiva para pessoas com deficiência abrem espaço, também, para a carreira paralímpica, sendo, muitas vezes, a porta de entrada 
Dossiê | A iniciação esportiva no esporte paralímpico: o caso do voleibol sentado (SANCHOTENE, Vitória Crivellaro; BATAGLION, Giandra Anceski; MAZO, Janice Zarpellon)

para o alto rendimento no esporte paralímpico (BATAGLION; MAZO, 2019a), como é o caso das atletas participantes desta pesquisa.

No âmbito da prática institucionalizada do voleibol sentado, a pessoa com deficiência é compreendida como elegível após passar por classificações funcionais e ser confirmado o seu diagnóstico de deficiência física dentro do sistema de classificação da modalidade. Este tipo de deficiência pode caracterizar-se pela diminuição da força muscular, limitações de movimentos, limitações nos membros, diferença no comprimento de membros, baixa estatura, hipertonia, ataxia, atetose, dentre outros comprometimentos (INTERNATIONAL PARALYMPIC COMMITTEE, 2015). No Brasil, de acordo com Ferreira (2014), os(as) atletas do voleibol sentado possuem, em sua maioria, amputações nos membros inferiores, as quais são oriundas, em muitos casos, de acidentes de trânsito.

Ao evidenciar elementos referentes ao processo de iniciação à prática esportiva das atletas investigadas, contribuímos para o reconhecimento de seus percursos até chegarem ao alto rendimento, tornando-se atletas representantes da seleção brasileira feminina de voleibol sentado. Expor as histórias e memórias destas mulheres, é uma forma de incentivar outras pessoas a conhecerem e praticarem a modalidade. Corroborando com o estudo de Bataglion et al. (2019), o qual identificou que atletas brasileiros(as) de variadas modalidades paralímpicas tiveram a sua iniciação à prática esportiva motivada por ídolos paralímpicos, isto é, por atletas com deficiência que representam o Brasil em grandes competições, como os Jogos Paralímpicos. Por sua vez, os estudos de Haiachi (2017) e Bertoldi et al. (2018) os quais também investigaram atletas paralímpicos brasileiros(as), apontaram aspectos como a escola e a família como propulsores e fundamentais para o ingresso e a permanência de pessoas com deficiência no esporte. Já, Cardoso (2016), traz a relevância de programas e projetos governamentais e não-governamentais para que a iniciação no viés do esporte paralímpico aconteça na fase escolar, visto que grande parte dos(as) atletas paralímpicos(as) brasileiros(as) tiveram este início na vida adulta.

Com base nestas considerações iniciais, este estudo tem como objetivo averiguar como ocorreu a inserção de atletas da seleção brasileira feminina de voleibol sentado na prática esportiva desta modalidade paralímpica. A fim de atender ao objetivo proposto, desenvolvemos o estudo a partir da perspectiva histórico-cultural, buscando 
Dossiê | A iniciação esportiva no esporte paralímpico: o caso do voleibol sentado (SANCHOTENE, Vitória Crivellaro; BATAGLION, Giandra Anceski; MAZO, Janice Zarpellon)

compreender particularidades e significados individuais (CRESWELL, 2010). Os procedimentos metodológicos adotados seguiram duas etapas, são elas: revisão de literatura e coleta de informações por meio de entrevista semiestruturada. Na primeira, fizemos uma busca por artigos, dissertações, teses e livros na base de dados Google Acadêmico, no Repositório Digital da Universidade Federal do Rio Grande do Sul (LUME) e no portal Scielo. Esta busca foi direcionada para que abrangesse assuntos sobre a iniciação esportiva em esportes paralímpicos e o voleibol sentado no Brasil. Publicações que possuíam, em seus títulos, resumos e palavras-chave, termos que pudessem contribuir com a presente pesquisa, foram incluídos.

Depoimentos sobre as memórias referentes aos percursos iniciais no esporte paralímpico foram coletadas por meio de entrevistas semiestruturadas com cinco atletas da seleção brasileira feminina de voleibol sentado, tendo foco nas experiências pessoais das atletas. O roteiro de entrevista foi elaborado com 12 questões abertas, sendo aplicado um mesmo roteiro para todas as participantes da pesquisa. As entrevistas foram gravadas e transcritas no ano de 2018, para posterior análise das informações e discussão com a bibliografia acessada sobre o tema.

As atletas assinaram um Termo de Consentimento Livre e Esclarecido (TCLE), aceitando participar voluntariamente do estudo e autorizando a divulgação de suas identidades na publicação dos resultados. Este estudo se constitui em um braço do projeto de pesquisa intitulado "Esportes adaptados e esportes paralímpicos no Brasil: estudos histórico-culturais e psicossociais", tendo sido aprovado pelo Comitê de Ética em Pesquisa da Universidade Federal do Rio Grande do Sul (CEP/UFRGS) sob o protocolo de número 27.331.

Frente ao exposto, organizamos o texto em dois tópicos: a) Deficiência e esporte paralímpico: percursos que se encontra(ram); b) Lembranças das atletas sobre a Educação Física escolar. Nestes tópicos, apresentamos as informações oriundas das entrevistas, contextualizando as formas com que as colaboradoras discorreram sobre seus percursos esportivos e discutindo os resultados encontrados a partir da revisão de literatura realizada acerca de nosso objeto de estudo. Neste interim, buscamos considerar as particularidades, bem como valorizar as experiências individuais. Deste modo, a pessoa que vivenciou as experiências pode ser protagonista de sua história, narrando-a. 
Dossiê | A iniciação esportiva no esporte paralímpico: o caso do voleibol sentado (SANCHOTENE, Vitória Crivellaro; BATAGLION, Giandra Anceski; MAZO, Janice Zarpellon)

\section{a) Deficiência e esporte paralímpico: percursos que se encontram}

Ao investigar os percursos esportivos de cinco atletas da seleção brasileira feminina de voleibol sentado, encontramos algumas similaridades e outras diferenciações entre suas iniciações esportivas no esporte paralímpico. Entendemos que há singularidades em histórias pessoais, especificamente influenciadas por contextos sociais e culturais distintos. Isto fez com que nos resultados deste estudo fossem evidenciados significados particulares quanto a inserção das mulheres investigadas na prática do voleibol sentado.

Identificou-se que dentre as cinco entrevistadas, apenas a atleta Suellen possui deficiência física congênita ${ }^{4}$. Portanto, quatro atletas possuem deficiência física adquirida, com a seguintes causas: acidente de moto (Ádria e Paula - amputação transtibial), atropelamento de automóvel (Jani - amputação transfemoral) e por erro médico (Gizele - torção de joelho/sem movimento no pé). Tais informações se fazem relevantes para este estudo, visto que a causa das deficiências influenciou o processo de inserção das atletas no esporte paralímpico.

O acidente, o trauma, a amputação, foram fatores de destaque para a atleta Jani que associa seu início na prática esportiva ao fato de ter passado por um acidente em que foi "atropelada por uma carreta" (JANI, 2018, p. 1). Este acidente ocorreu no interior do estado de Goiás, no ano de 2006, quando a entrevistada tinha 20 anos de idade. Em decorrência da gravidade do acidente, tornou-se necessária a amputação transfemoral (acima do joelho) no terço médio do membro inferior esquerdo. Ao lembrar do acidente, Jani explica: "perdi muito sangue, meu caso foi muito grave, muito! Morava no interior e o acidente foi nove horas da manhã. Eu cheguei ao hospital de base em Brasília meia noite" (JANI, 2018, p. 2). Jani, que residia na cidade onde ocorreu o acidente, três meses após a amputação e cicatrização, foi morar em Goiânia.

A atleta Jani lembra que foi na loja de ortopedia, onde estava passando pelo processo de protetização ${ }^{5}$, que ocorreu seu primeiro contato com a modalidade do

\footnotetext{
${ }^{4}$ A deficiência congênita pode ter origem no período pré ou neo natal.

${ }^{5}$ A protetização ocorre após a amputação, objetivando o desenvolvimento das atividades de vida diária com a máxima independência e funcionalidade do indivíduo, utilizando-se, para isto, próteses em substituição aos membros amputados - por exemplo, o uso de pernas mecânicas. Ressalta-se que a
} 
Dossiê | A iniciação esportiva no esporte paralímpico: o caso do voleibol sentado (SANCHOTENE, Vitória Crivellaro; BATAGLION, Giandra Anceski; MAZO, Janice Zarpellon)

voleibol sentado. Um profissional (protético) desta loja explicou a ela sobre a possibilidade de praticar esporte para pessoas com deficiência física. Sabendo da existência da modalidade do voleibol sentado, este profissional apresentou Jani ao técnico da equipe de voleibol sentado de Goiânia/GO, José Agtônio Guedes ${ }^{6}$, o qual fez o convite para que Jani conhecesse a modalidade do voleibol sentado. Isto ocorreu no ano de 2007, um ano após o acidente de Jani. A atleta relatou que iniciou os treinamentos com a equipe no ano de 2007 e, no ano seguinte, começou a participar de viagens com a seleção brasileira de voleibol sentado. Jani comenta que levou por volta de um ano para se familiarizar com a modalidade.

Para Benfica (2012) o convite do treinador é um dos fatores para que a pessoa com deficiência busque se engajar e se aperfeiçoar em alguma modalidade paralímpica. Nesta direção, frequentemente a aderência de pessoas com deficiência no esporte é influenciada por "programas de reabilitação, por técnicos, treinadores envolvidos no paradesporto e por familiares que conheciam o esporte adaptado" (BENFICA; 2012, p. 9). Especialmente, nos casos em que a pessoa adquire a deficiência na idade adulta, é comum que receberam indicações sobre as modalidades paralímpicas pelos seus médicos, fisioterapeutas ou por pessoas ligadas a associações esportivas. Exemplo disso foi o caso da atleta Jani, que teve indicação para a prática através de profissionais que a atenderam durante seu processo de protetização.

Jani relatou que seu protético também era amputado e isso contribuiu para que houvesse o direcionamento dela para a prática esportiva. Esse indício aponta a relevância de que a sociedade tenha conhecimento sobre os esportes adaptados e paralímpicos, de modo a contribuir para a sua difusão, sobretudo, às pessoas com deficiência. Vale ressaltar que os contextos de reabilitação possuem proeminente papel para o engajamento das pessoas com deficiência, seja congênita ou adquirida, em práticas esportivas. A área da educação física, em atuação interdisciplinar com outras áreas da saúde - fisioterapia, terapia ocupacional, nutrição, psicologia, etc. - tem a

protetização requer um período de adaptação do indivíduo à prótese. Sobre isto, a atleta Jani comentou que seu processo de protetização e adaptação foi rápido, por conta de seu convênio particular de saúde que cobria o valor da prótese.

6 José Agtônio Guedes foi treinador da seleção brasileira feminina de voleibol sentado nos Jogos Paralímpicos no Rio de Janeiro em 2016. É o atual treinador da seleção brasileira feminina de voleibol sentado e o qual continua como um dos treinadores de voleibol sentado da capital de Goiás. 
Dossiê | A iniciação esportiva no esporte paralímpico: o caso do voleibol sentado (SANCHOTENE, Vitória Crivellaro; BATAGLION, Giandra Anceski; MAZO, Janice Zarpellon)

função de inserir a pessoas com deficiência em atividades esportivas ainda no período e no ambiente de reabilitação e, encaminhá-la para programas ou projetos esportivos ou de atividades motoras, que possuam objetivos adequados à faixa etária e ao tipo de deficiência da pessoa, visando contribuir para o alcance máximo da sua independência e inclusão social.

Sobre quando conheceu a modalidade do voleibol sentado, Jani comenta: “... apaixonei e a primeira vez que eu fui, mesmo, para conhecer a novidade, eu fiquei encantada" (JANI, 2018, p. 1). Também, em sua narrativa sobre a iniciação esportiva paralímpica, conhecer outras pessoas com deficiência foi algo que destacou, pois Jani não conhecia outras pessoas com amputação. Sendo assim, isto contribuiu para o seu processo individual de entendimento acerca da deficiência:

Como morava no interior, eu não via, acho que os olhos não eram treinados para isso. A partir do momento que eu conheci a $\mathrm{ADFEGO}^{7}$ - lá tem vários tipos de esporte -, então, tem muito deficiente, não era só amputado de braço, perna, cadeirante. Foi um choque para mim. Eu fiquei encantada, eu falei assim: gente, não sou só eu no mundo, tem mais pessoas. E conheci o voleibol e me apaixonei (JANI, 2018, p. 1).

Assim como a atleta Jani, que teve indicação para a prática do voleibol sentado através de um profissional que a atendeu durante seu processo de protetização, a atleta Paula relatou que iniciou o contato com a modalidade a partir da indicação de seu médico. Isto ocorreu no Centro de Reabilitação de São Paulo, durante o processo de protetização, em 2011, por conta de um acidente de moto ocorrido no ano de 2005 que levou à amputação transtibial (abaixo do joelho). A indicação foi para a prática no Clube dos Paraplégicos ${ }^{8}$ de São Paulo, pois, na época, o médico tinha o contato de uma pessoa que buscava "talentos paralímpicos"9 para a modalidade do voleibol sentado.

\footnotetext{
${ }^{7}$ Associação dos Deficientes Físicos do Estado de Goiás.

${ }^{8}$ Um dos primeiros clubes fundados para a prática de modalidade paralímpica no Brasil, no ano de 1958, quando iniciou com a prática do basquetebol em cadeira de rodas. No mesmo período, foi fundado o clube do otimismo, no Rio de Janeiro, com a prática da mesma modalidade (CARDOSO et al., 2017).

${ }^{9}$ Para fins deste estudo, o termo "talentos paralímpicos" se refere aquelas pessoas com deficiência que apresentam alto desempenho em modalidades paralímpicas, podendo se constituir em potenciais atletas para representar o país em competições esportivas, como os Jogos Paralímpicos. A busca por talentos paralímpicos no Brasil, na época em que as atletas investigadas iniciaram no voleibol sentado, ocorria, de forma geral, por meio de indicações - o chamado boca a boca -, como observamos nos relatos de nossas entrevistadas. Isto porque, pelo menos em âmbito nacional, o país teve os seus primeiros programas e projetos no viés da iniciação esportiva paralímpica idealizados e iniciados no ano de 2006 pelo CPB,
} 
Dossiê | A iniciação esportiva no esporte paralímpico: o caso do voleibol sentado (SANCHOTENE, Vitória Crivellaro; BATAGLION, Giandra Anceski; MAZO, Janice Zarpellon)

A deficiência adquirida da atleta Gizele se deu de forma diferente das duas atletas supracitadas. Gizele teve uma torção no joelho e conta ter se sentido "perdida" após os médicos terem dito que ela nunca mais poderia "praticar esporte, saltar, nem correr, nem fazer nada..., porque a patela estava muito porosa, toda cheia de problemas" (GIZELE, 2018, p. 1). Essa torção no joelho de Gizele foi oriunda de uma cirurgia mal sucedida, onde a atleta ficou sem o movimento de um dos pés. Gizele $(2018$, p. 1) recorda: “[...] não podia mais fazer esporte! Médicos ignorantes, porque eles não sabem do paradesporto. Quase entrei em depressão [...]". Gizele comentou que era praticante do voleibol desde os nove anos de idade e que torceu o joelho aos 30 anos, além disso relatou como era a sua relação com o voleibol antes e após adquirir a deficiência:

"Era a minha vida, eu adorava aquilo, eu respirava. Não me via fora da quadra, apesar de ser voleibol amador, eu era competitiva, estava em campeonatos, disputando jogos regionais com as minhas cidades lá e tal... Nunca joguei pela minha cidade, joguei pela cidade dos outros. (Risos) Joguei por Ferraz 11 anos. E os médicos falaram que eu não poderia mais praticar esporte, entrei em depressão. Aí, falei com um amigo meu, conversando com ele, então: por que você não vem pro vôlei sentado? para deficientes. Aí eu falei: nossa, mas será que eu me encaixo?" (GIZELE, 2018, p. 1).

A partir do trecho presente na fala de Gizele "Será que eu me encaixo?", podemos perceber que os assuntos acerca dos esportes paralímpicos e sobre as classificações funcionais de cada modalidade devem ser mais debatidos e levados à sociedade por intermédio de artefatos como a mídia, as instituições de ensino, entre outros formas de divulgação. Cardoso et al., (2018) ressaltam que o esporte paralímpico, ao ser explorado pela mídia, gerou incentivo a novos atletas. Desta forma, um maior investimento do setor midiático com relação aos esportes paralímpicos pode colaborar com as equipes para adquirirem novos atletas, bem como podem trazer novos apoiadores e/ou patrocínios para as equipes, além de diminuir os estereótipos que ainda existem acerca da pessoa com deficiência, aumentando as suas possibilidades de inclusão.

tornando esta fase de ingresso na carreira paralímpica, gradativamente, mais sistematizada (BATAGLION; MAZO, 2019a). Atualmente, o Planejamento Estratégico do CPB contempla variados programas e projetos de iniciação esportiva. No âmbito estadual e municipal, este trabalho parece ser conduzido, sobretudo, por associações, projetos sociais e, em alguma medida, por professores de educação física escolar engajados na promoção do esporte para a pessoa com deficiência (BATAGLION; MAZO, 2019b). 
Dossiê | A iniciação esportiva no esporte paralímpico: o caso do voleibol sentado (SANCHOTENE, Vitória Crivellaro; BATAGLION, Giandra Anceski; MAZO, Janice Zarpellon)

As atletas Jani e Paula destacaram os papeis do médico, do protesista, dos professores e treinadores. Por sua vez, no depoimento de Gizele, aparece um novo personagem: o amigo. Vagner, é o amigo citado por Gizele, o qual é integrante da seleção brasileira masculina de voleibol sentado e direcionou Gizele para treinar no Serviço Social da Indústria de São Paulo (SESI-SP). Para isso, o atleta Vagner colocou Gizele em contato com o treinador Ronaldo Gonçalves de Oliveira ${ }^{10}$, no ano de 2009, três anos após ela ter se afastado da prática esportiva devido ao acidente médico ocorrido. Ronaldo levou Gizele à fisioterapeuta do clube SESI/SP, a qual analisou sua deficiência e observou que poderia ser considerada a Classe Esportiva VS2 no voleibol sentado, na época chamada de mínima deficiência (FERREIRA, 2014). Deste modo, a fisioterapeuta solicitou os exames que seriam necessários para o processo de classificação.

Dentre as 12 atletas que são escaladas para competir em uma disputa de voleibol sentado, pode haver duas atletas da Classe Esportiva VS2 e, dentro de quadra apenas uma atleta com essa classificação funcional pode estar jogando. A atleta Gizele, ao lembrar da expectativa que criou ao pensar em ser elegível para a prática do voleibol sentado, disse: “já brilhou uma estrela comigo" (GIZELE, 2018, p. 2). Nota-se a expectativa e emoção de poder praticar esporte novamente, sendo que o voleibol era uma prática de muita importância na vida de Gizele.

Podemos perceber que a figura do treinador aparece nos discursos das atletas entrevistadas e isso também ocorreu na fala da atleta Ádria, que conheceu o treinador José Agtônio Guedes e iniciou os treinamentos dentro da ADFEGO, local onde passou a trabalhar após adquirir deficiência física. Ádria, natural de Goiânia/GO, sofreu um acidente de moto e passou por cirurgia de amputação transfemoral esquerda. Este acidente ocorreu quando a atleta tinha 16 anos. Ádria recorda: "nunca tinha convivido com pessoas com deficiência" (ÁDRIA, 2018, p. 2).

Ádria relatou que levou três anos para "protetizar" e para "sair para o mundo" (ÁDRIA, 2018, p. 2), denotando um longo processo, principalmente devido ao alto custo da prótese. Vale destacar que quanto maior o tempo de protetização e de adaptação após a pessoa adquirir uma deficiência, mais tardia será a inserção em alguma prática

\footnotetext{
${ }^{10}$ Ronaldo Gonçalves de Oliveira foi treinador da seleção brasileira feminina de voleibol sentado nos Jogos Paralímpicos de Londres (Inglaterra), em 2012.
} 
Dossiê | A iniciação esportiva no esporte paralímpico: o caso do voleibol sentado (SANCHOTENE, Vitória Crivellaro; BATAGLION, Giandra Anceski; MAZO, Janice Zarpellon)

esportiva ou em atividades físicas em geral. Além disso, o prolongamento deste processo prejudica a sua independência e inclusão nas atividades sociais. Quando Ádria começou a trabalhar na ADFEGO, viu essa como "a primeira porta que se abriu" (ÁDRIA, 2018 , p. 2). No ano de 2005, enquanto trabalhava, Ádria encontrou o treinador José Agtônio Guedes:

De cara me viu e já fez o convite para conhecer o vôlei sentado e, assim, fiquei meio receosa de início, porque não sei jogar, não sei pegar na bola, eu nunca fui de praticar nenhuma atividade física. O que é fazer uma manchete? Toque? Deslocamento? Foi um período que eu falei assim: não, não, não vou dar conta, isso não é para mim (ÁDRIA, 2018, p. 3).

Ádria informou que não conhecia a modalidade paralímpica do voleibol sentado antes do convite feito por José Agtônio Guedes. Porém, ao receber o convite do treinador, a atleta se dispôs a conhecer o voleibol sentado, por curiosidade. Conforme Cardoso (2016), a iniciação esportiva de pessoas com deficiência está amplamente relacionada, em primeiro lugar, a oportunidade de prática, e; em segundo lugar, ao prazer oriundo da prática esportiva. Nota-se, assim, que é recorrente a forma de aproximação dos atletas no meio paralímpico através de convites de treinadores e professores, entendida por Cardoso $(2016$, p. 36) como "maneira informal que favorece o ingresso...", apontando que esta forma gera resultados positivos para o processo de iniciação.

A atleta Ádria ressaltou que uma de suas dificuldades nos primeiros momentos em contato com o voleibol sentado foi o deslocamento no chão. Fernandes (2019, p. 32) explica que quando se discute a iniciação esportiva em esporte para pessoa com deficiência adquirida, mostra-se uma vertente ligada à "re(construção) de caminhos", por conta da descoberta de uma nova situação, em um "contexto diferenciado" e também por ter passado por modificações em seu corpo. Por estes, dentre outros motivos, a introdução das pessoas com deficiência adquirida em modalidades do esporte paralímpico pode ser tardia em relação às pessoas com deficiência congênita. Assim como mostram os achados da pesquisa de Haiachi (2017, p. 109), em que os atletas participantes citam que "tinham duas vidas: antes da lesão e depois da lesão", indicando que as pessoas com deficiência adquirida passam por momentos de 
Dossiê | A iniciação esportiva no esporte paralímpico: o caso do voleibol sentado (SANCHOTENE, Vitória Crivellaro; BATAGLION, Giandra Anceski; MAZO, Janice Zarpellon)

adaptação à nova condição - de pessoa com deficiência. Nesta perspectiva, há uma parcela de pessoas com deficiência, especialmente de causa adquirida, que iniciam a prática de modalidades paralímpicas, visando a reabilitação não apenas física, mas psicossocial (PALACIOS et al., 2014; CARDOSO, 2016).

Pensando em uma possível chance de Ádria ser convocada para a seleção brasileira feminina de voleibol sentado, por conta de motivações vindas do treinador José Agtônio Guedes - que elogiava sua estatura e envergadura -, a atleta se empenhou desde o início dos treinamentos. Ádria disse que não sabia os fundamentos do voleibol convencional $^{11}$ e que com o tempo e com o incentivo do treinador, ela sentiu sua melhora. Tais relatos denotam que os treinadores se configuram em agentes essenciais no processo de iniciação esportiva de atletas paralímpicos(as), o que perdura nas fases de treinamento e competição (BATAGLION; MAZO, 2019a). Neste cenário de incentivos do treinador e de dedicação da atleta aos treinos, um ano após o início na modalidade, em 2006, em um campeonato brasileiro, Ádria conquistou o prêmio destaque como melhor bloqueadora da competição e, em seguida, foi convocada para a seleção brasileira feminina de voleibol sentado.

Diferentemente das atletas supramencionadas, a atleta Suellen possui deficiência congênita. Suellen teve, possivelmente, o seu cordão umbilical preso a uma de suas mãos no período neo natal, culminando na má formação deste membro. Suellen registra: "quando você nasce é mais fácil", pois "não se sabe como é ter duas mãos". Assim sendo, afirma: "eu consigo fazer tudo, acho que algumas coisas mais adaptadas que outras..." (SUELLEN, 2018, p. 4). Suellen iniciou aos 11 anos a prática do voleibol convencional, jogando em pé: “Na verdade, eu jogava, brincava na rua de vôlei, desde pequena. Um dia uma amiga minha falou "eu vou fazer escolinha", aí falei para a minha mãe: também quero fazer escolinha de vôlei (SUELLEN, 2018, p. 1).

A atleta Suellen participou de campeonatos jogando voleibol convencional. No primeiro momento, participou da escolinha acima referida, mas por questões financeiras teve que interromper tal participação. Depois, ela conta que foi praticar voleibol convencional na escolinha da prefeitura e jogava pela cidade em que morava, Diadema/SP. Sobre seu início no voleibol sentado, assim como as demais entrevistadas,

\footnotetext{
${ }^{11}$ Os fundamentos do voleibol convencional são os mesmos que o do voleibol sentado.
} 
Dossiê | A iniciação esportiva no esporte paralímpico: o caso do voleibol sentado (SANCHOTENE, Vitória Crivellaro; BATAGLION, Giandra Anceski; MAZO, Janice Zarpellon)

Suellen destaca a importância do treinador nesse processo. Ao jogar um campeonato, um árbitro que conhecia o treinador Ronaldo Gonçalves de Oliveira, mesmo treinador citado pela atleta Gizele, e que sabia que ele trabalhava com voleibol sentado, ao ver a deficiência de Suellen e ao vê-la jogando voleibol convencional, comentou com o referido treinador: "Em Diadema tem uma menina que não tem a mão e que joga vôlei" (SUELLEN, 2018, p. 1).

Segundo a atleta, a partir disso o treinador Ronaldo ligou para a secretaria de esportes de Diadema/SP e obteve o telefone do treinador de voleibol da equipe na qual Suellen treinava. A partir da conversa que ambos os treinadores tiveram, Suellen foi convidada para experimentar o voleibol sentado: "meu técnico que me ligou e acabei indo pra Suzano pra conhecer, pra ver, em 2006" (SUELLEN, 2018, p. 1). A atleta Suellen relatou que percebeu dificuldades ao passar da modalidade do voleibol convencional para o voleibol sentado, pois considera que "no sentado eu perdia porque eu tenho as duas pernas e sentado eu me igualo a quem não tem e perco porque fica mais pesado para você se deslocar", e; explica: "perdia porque não tinha mão, bloqueio, toque" (SUELLEN, 2018, p. 2).

Embora a fala de Suellen revele certo sentimento de desvantagem em relação as demais atletas no período de sua iniciação no voleibol sentado, sua experiência prévia no voleibol convencional, possivelmente, contribuiu para a progressão de seu desempenho nessa modalidade paralímpica. Dantas (2018) corrobora com esta ideia, ressaltando que as atletas terem tido uma formação no voleibol convencional e migrar para o paralímpico colabora para a adaptação e o resultado delas no esporte. As cinco atletas entrevistadas nesta pesquisa iniciaram na modalidade do voleibol sentado, em sua primeira década de desenvolvimento no Brasil, nos anos 2000. Neste sentido, as memórias narradas pelas atletas no ano de 2018, fazem referência aos primórdios dessa modalidade no país. Os dois treinadores citados nesse artigo são profissionais atuantes do movimento paralímpico até os dias atuais (2020) e as entidades referidas ao longo do texto também continuam ativas.

Begossi e Mazo (2016) também destacam atletas enquanto sujeitos históricos. As autoras investigaram percursos esportivos por meio de fontes orais de mulheres atletas pioneiras sul-rio-grandenses nas décadas de 70 e 80 . Em seus resultados e discussões puderam perceber que no estado do Rio Grande do Sul, em especial na cidade de Porto 
Dossiê | A iniciação esportiva no esporte paralímpico: o caso do voleibol sentado (SANCHOTENE, Vitória Crivellaro; BATAGLION, Giandra Anceski; MAZO, Janice Zarpellon)

Alegre, os institutos e associações foram influenciadores para o início e inserção da prática no esporte paralímpico, mais especificadamente no para atletismo. Portanto, sublinha-se o fato de que, apesar das singularidades históricas, diferenças de períodos históricos investigados, distintos lugares do país sendo foco da pesquisa, bem como outra modalidade estudada, compreende-se a importância de entidades e instituições para o desenvolvimento da prática esportiva paralímpica no Brasil.

Compreende-se que a iniciação esportiva dessas cinco atletas da seleção brasileira feminina de voleibol sentado traz indícios relevantes para compreendermos algumas maneiras de ingresso nesta prática no Brasil, sobretudo, na década de 2000. Cada história traz suas particularidades, pois não se pode fazer generalizações acerca dos percursos esportivos, visto que cada indivíduo apresenta vivências distintas e, portando, versões diversas e próprias de sua realidade. De tal modo, afora os treinadores e as entidades esportivas, evidenciados neste tópico como agentes catalizadores na iniciação esportiva das atletas, as experiências vividas nas aulas de Educação Física escolar despontaram como uma categoria evidenciada neste estudo, conforme o tópico que segue.

\section{b) Lembranças das atletas sobre a Educação Física escolar}

As experiências vividas nas aulas de Educação Física escolar podem interferir, de forma positiva ou negativa, o processo de iniciação esportiva em modalidades do esporte paralímpico. Isto se faz relevante tanto para as pessoas com deficiência congênita - que desde a fase escolar devem ser estimuladas e atendidas em suas necessidades a fim de explorarem os aspectos globais de seu desenvolvimento por meio da Educação Física -, quanto para as pessoas com deficiência adquirida - que desfrutarão de maiores possibilidades e facilidade para o engajamento e o desempenho em modalidades paralímpicas após se encontrarem em condição de pessoa com deficiência. Para tanto, Educação Física escolar demanda de práticas pedagógicas diversificadas, respeitando-se às individualidades (BELTRAME; SAMPAIO, 2015).

Para a atleta Jani, os conhecimentos prévios aprendidos na escola com o voleibol convencional contribuíram para o seu desempenho na iniciação esportiva do voleibol sentado. Os movimentos como gestos técnicos, fundamentos da modalidade, bem 
Dossiê | A iniciação esportiva no esporte paralímpico: o caso do voleibol sentado (SANCHOTENE, Vitória Crivellaro; BATAGLION, Giandra Anceski; MAZO, Janice Zarpellon)

como o entendimento da lógica do jogo e o gosto pelo esporte foram importantes para ela nesse momento inicial da prática esportiva adaptada. A atleta comenta: "Você tem ideia, eu sabia fazer um pouco de fundamento por causa da escola, a gente brincava na escola, na educação física, então sabia um pouquinho e sempre gostei..." (JANI, 2018, p. 1).

Os estudos de Beltrame e Sampaio (2015), Haiachi (2016) e Cardoso (2017) também apresentam dados em que atletas paralímpicos(as) de diferentes modalidades destacam as influências das aulas da Educação Física escolar para o ingresso e a permanência no esporte. Os autores, que obtiveram resultados apontando a relevância da Educação Física escolar, expõem resultados semelhantes para pessoas com deficiências congênitas ou adquiridas. Além disso, o estudo de Bertoldi et al. (2018) referente aos fatores psicológicos de uma atleta paralímpica com deficiência adquirida, identificou resultados, indicando que as práticas esportivas vivenciadas e apreendidas pelos(as) alunos nas aulas de Educação Física escolar causam reflexos ao longo de toda a vida da pessoa. Tal informação se observou também nos relatos da atleta Jani, que apresentou percepções positivas sobre o seu engajamento no voleibol sentado desde os primeiros contatos com a prática da modalidade, atribuindo isto, em certa medida, aos ensinamentos que recebeu sobre o voleibol na fase escolar.

Assim como Jani, Paula referiu conhecimentos prévios sobre o voleibol convencional, os quais foram adquiridos nas aulas de Educação Física escolar. Paula mencionou que também conhecia a existência da modalidade paralímpica do voleibol sentado, mas que não imaginava que jogaria um dia. Ressaltou que ingressou no voleibol sentado como uma prática de lazer, mas que acabou tendo a oportunidade de participar de Jogos Paralímpicos. Neste sentido, Fernandes $(2019$, p. 16) explicita que o processo de iniciação das pessoas com deficiência no esporte é complexo por ter diferentes fases que "envolvem desde a aproximação, aceitação, entendimento, incorporação da prática esportiva e por último a transformação em praticante do esporte". No caso de Paula, seu percurso convergiu para a carreira paralímpica.

Fernandes (2019), aponta, também, que a iniciação esportiva no esporte olímpico e no esporte paralímpico tem sentidos semelhantes, porém no esporte paralímpico existem diferenças relacionadas a locais de práticas, materiais utilizados, equipamentos necessários e diferem também no que tange a incentivos, corroborando com os relatos 
Dossiê | A iniciação esportiva no esporte paralímpico: o caso do voleibol sentado (SANCHOTENE, Vitória Crivellaro; BATAGLION, Giandra Anceski; MAZO, Janice Zarpellon)

das atletas quanto as condições de prática vivenciadas ao ingressarem no voleibol sentado. Cardoso (2016) corrobora ao referir que, no esporte paralímpico, a fase de iniciação esportiva do(a) atleta é atravessada por algumas barreiras como falta de recursos financeiros, de estrutura esportiva e de profissionais qualificados para ensinar a modalidade escolhida. Soma-se a isto, conforme as respostas de nossas entrevistadas, as dificuldades para a adaptação à modalidade aderida. Diante das condições que o(a) atleta pode enfrentar para permanecer no esporte paralímpico, é comum que haja desistência, conforme Cardoso (2016). Neste sentido, uma Educação Física escolar de qualidade - que contemple para além da prática esportiva, colocando, por exemplo os valores paralímpicos em discussão ${ }^{12}$-, pode contribuir para que tais obstáculos sejam enfrentados e superados na fase de iniciação esportiva, evitando o abandona da prática.

Paula destacou a importância de divulgar mais o esporte paralímpico e conta que, muitas vezes, é convidada para compartilhar sua experiência com professores e com as crianças na escola. Sobre isto, o estudo de Resende (2018), aponta que os relatos de atletas paralímpicos brasileiros são relevantes para se promover o engajamento de novos adeptos à prática das modalidades. Sobretudo, para crianças e jovens com deficiência, a figura do ídolo paralímpico suscita representações de superação e sucesso, congregando novos praticantes e quiçá, descobrindo futuros atletas paralímpicos. Todavia, há de se considerar que um pequeno percentual destas crianças e jovens com deficiência chegarão à posição de atletas profissionais.

Não apenas os estudantes com deficiência devem ser motivados a praticar esportes paralímpicos. Estas modalidades precisam ser incorporadas aos conteúdos da Educação Física escolar a fim de que se tornem conhecidas na sociedade, favorecendo o seu reconhecimento social e a aderência de pessoas com deficiência, seja congênita ou adquirida. Destaca-se que, das cinco atletas entrevistadas neste estudo, nenhuma referiu ter conhecimento prévio acerca do voleibol sentado antes de receber o convite

\footnotetext{
12 Os valores paralímpicos são: a) Coragem: engloba o espírito único do atleta paralímpico, que busca realizar o que a sociedade considera inesperado e impossível, mas que o atleta reconhece como uma realização possível; b) determinação: capacidade que os atletas paralímpicos demonstram na busca do limite máximo de suas potencialidades; c) igualdade: o esporte paralímpico atua como agente de mudanças e transformação e como instrumento para a quebra de barreiras sociais, discriminação e preconceitos para com a pessoa com deficiência; inspiração: o intenso sentimento pessoal nasce a partir das realizações e histórias de vida dos atletas paralímpicos (INTERNATIONAL PARALYMPIC COMMITTEE, 2019).
} 
Dossiê | A iniciação esportiva no esporte paralímpico: o caso do voleibol sentado (SANCHOTENE, Vitória Crivellaro; BATAGLION, Giandra Anceski; MAZO, Janice Zarpellon)

e ingressar na prática. Compreende-se que tais respostas possuem relação com a realidade do esporte paralímpico e, em especial, do voleibol sentado na época em que estas pessoas adquiriram suas deficiências. Época esta, em que havia carência de programas e projetos de âmbito nacional focados na iniciação ao esporte paralímpico. Tal assunto, era praticamente desconhecido nas escolas brasileiras. Por este e por inúmeros outros motivos, grande parte dos(as) atletas paralímpicos(as) brasileiros(as) iniciantes no mesmo período das investigadas, tiveram suas iniciações esportivas nas devidas modalidades paralímpicas na vida adulta.

Tal cenário começou a passar por transformações, sobretudo, a partir da criação de um projeto do esporte paralímpico escolar de nível nacional, o qual foi idealizado pelo Comitê Paralímpico Brasileiro (CPB) no ano de 2006, o Projeto Paraolímpicos do Futuro $^{13}$ (BATAGLION; MAZO, 2019a). A partir disto, outras iniciativas foram implementadas pelo CPB, como o evento Paralimpíadas Escolares, o Projeto Clube Escolar Paraolímpico, o Centro de Formação Esportiva em Esportes Paralímpicos, o Camping Paralímpico escolar, o Festival Paralímpico, dentre outras ações ${ }^{14}$. É possível que este conjunto de ações tenha atuado na promoção do esporte paralímpico nos contextos escolares do país, além de abrir espaços para a iniciação esportiva às crianças e aos jovens com deficiência em entidades que já desenvolviam modalidades paralímpicas, todavia, contemplando apenas participantes adultos (BATAGLION; MAZO, 2019b). Vale frisar que a difusão do esporte paralímpico entre escolares já conquistou certa visibilidade no Brasil, todavia, ainda carece de espaço, sobretudo, nas escolas. Para tanto, os(as) professores(as) de Educação Física precisam estar dispostos a atuar na

\footnotetext{
13 No ano de 2006, o CPB deu início às iniciativas de fomento ao esporte para crianças e jovens com deficiência, sobretudo, com enfoque na escola. Por meio do Projeto intitulado Paraolímpicos do Futuro, a entidade passou a realizar capacitações à professores(as) de Educação Física sobre o esporte paralímpico em todas as regiões geográficas do Brasil, ressaltando a importância e as possibilidades de sua inserção nas aulas de Educação Física escolar (CONDE; SOBRINHO; SENATORE, 2006). Além dos objetivos relativos à inclusão social das pessoas com deficiência por meio do esporte, o projeto carregava intenções atreladas a descoberta de talentos paraolímpicos. Isto teve início quando o CPB identificou que grande parte dos atletas paraolímpicos brasileiros, em atuação naquela época, tiveram acesso ao esporte paralímpico quando já eram adultos. Paralelamente a isto, a entidade deveria encontrar uma forma de aplicar parte dos recursos obtidos por intermédio da Lei $n^{\circ}$ 10.264, de 2001 (Lei Agnelo/Piva) ao viés do esporte escolar, desencadeando a criação deste e de sucessivos projetos e ações no âmbito escolar (GORLA; CALEGARI, 2017; BATAGLION; MAZO, 2019a).

${ }^{14}$ Para ter acesso a informações sobre as iniciativas citadas, ler: BATAGLION, Giandra Anceski; MAZO, Janice Zarpellon. Paralimpíadas Escolares (2006-2018): Evidências em mídias digitais acerca do evento esportivo. Recorde - Revista de História do Esporte, Rio de Janeiro/RJ, v. 12, n. 1, p. 1-42, 2019a.
} 
Dossiê | A iniciação esportiva no esporte paralímpico: o caso do voleibol sentado (SANCHOTENE, Vitória Crivellaro; BATAGLION, Giandra Anceski; MAZO, Janice Zarpellon)

perspectiva da Educação Física Inclusiva, considerando as possibilidades individuais e garantindo a participação de todos(as).

Ressignificar os espaços das aulas de educação física escolar, abrindo espaços para se compartilhar estratégias, tentativas, socializar os medos e angustias, problematizar mitos e tabus e criar coletivamente formas para se estabelecer a inclusão nas aulas, é essencial para se chegar a uma educação física que seja, de fato, inclusiva (GREGUOL; COSTA, 2019). Ainda, cabe destacar que a inclusão escolar de êxito envolve toda a comunidade escolar, onde as práticas e representações individuais e coletivas devem direcionar para o incluir amparado no ser ou invés do estar da pessoa com deficiência na escola. Assim, é fundamental que o espírito coletivo, a cooperação, o respeito às diferenças e a valorização da diversidade sejam adotadas como práticas culturais no interior dos contextos escolar e que, para além disto, extrapolem os estes espaços, assumindo reflexos à sociedade em geral.

Nesta perspectiva, a forma como a prática esportiva é apresentada e vivenciada pela pessoa, dentro ou fora da escola, pode suscitar o sentimento de satisfação ou desgosto, definindo, muitas vezes, se haverá permanência ou abandono quanto a modalidade. Isto pode ser observado nos relatos de Ádria que, ao ser questionada sobre a Educação Física escolar, mencionou: "Eu era, assim, uma pessoa bem leiga em questão de esporte. Nunca me importei, porque em escola, mesmo, eu nem gostava, nem gostava de educação física (risos)" (ÁDRIA, 2018, p. 3). Porém, ao receber o convite do treinador José Agtônio Guedes, a atleta se dispôs a conhecer o voleibol sentado, por curiosidade. Após todo o percurso que trilhou, se constituindo em atleta paralímpica, Ádria diz que passou a defender que "a educação física tem que ser obrigatória, porque a educação física pode mudar a vida de uma criança" (ÁDRIA, 2018, p. 9), entendendo que a sua iniciação no voleibol sentado poderia ter sido facilitada se experiencias de qualidade tivessem sido vivenciadas na Educação Física escolar.

Nesta lógica, Beltrame e Sampaio (2015, p. 378) elucidam que "o esporte e o seu processo de iniciação podem oportunizar um processo de democratização dos espaços oferecendo várias possibilidades para sua prática" e sublinham que a iniciação esportiva "deve configurar, sobretudo, uma oportunidade educativa que encaminhe o aluno ao sentido da prática corporal". Além da iniciação esportiva estimulada pela Educação Física escolar, outros fatores podem contribuir para esse processo. Neste sentido, vale 
Dossiê | A iniciação esportiva no esporte paralímpico: o caso do voleibol sentado (SANCHOTENE, Vitória Crivellaro; BATAGLION, Giandra Anceski; MAZO, Janice Zarpellon)

ressaltar o exposto de Silva (2007, p. 8): “as práticas corporais na população com deficiência são adequações contínuas de ajustamento, principalmente pela individualidade de cada praticante." A autora destaca que o esporte adaptado leva em conta as particularidades das pessoas com deficiência. Deste modo, além das possibilidades e necessidades da pessoa, é preciso atentar para os interesses (WINNICK, 2010).

No cenário do esporte paralímpico brasileiro atual, - diferentemente de outros períodos históricos, nos quais as oportunidades de prática esportiva às pessoas com deficiência eram reduzidas -, pode-se dizer que são diversificadas as modalidades em que as pessoas com cada tipo de deficiência podem se engajar por intermédio da escola, de projetos sociais, de associações e clubes esportivos ou de instituições especializadas (BATAGLION; MAZO, 2019c). Neste contexto, vale referir que a Lei $n^{\circ} 10.264$, de 2001 (Lei Agnelo/Piva) trouxe benefícios tanto para o alto rendimento no esporte paralímpico quanto para abrir espaços a iniciação esportiva às pessoas com deficiência, uma vez que parte dos recursos, destinados ao CPB por meio desta lei, são destinados ao fomento do esporte à estudantes com deficiência em idade escolar (REIS; MEZZADRI; SILVA, 2017). De tal modo, desde o ano de 2006 programas e projetos para crianças e jovens com deficiência foram implementados no país, conforme já mencionado (BATAGLION; MAZO, 2019a). Ademais, o desenvolvimento de centros de treinamento em esportes paralímpicos, bem como a criação de competições em nível escolar - nacional, regional e local - caracterizam o incentivo de órgãos como o CPB para o aumento da captação do público nas modalidades paralímpicas. Assim sendo, aumenta o número de atletas na base e as perspectivas para futuras seleções paralímpicas brasileiras (CONDE, 2018).

As iniciativas supramencionadas promovem visibilidade às pessoas com deficiência, contribuindo para a alteração de suas representações frente à sociedade. À Educação Física inclusiva pode aproveitar estes projetos, eventos e ações para evidenciar as potencialidades dos estudantes com deficiência, reforçando o esporte como um bem cultural e como direto para todos. As aulas de Educação Física não podem se tornarem espaços de treinamento ao esporte paralímpico, mas, sim, serem utilizadas como lugar oportuno para se mostrar as possibilidades existentes. Modalidades paralímpicas, como o voleibol sentado, podem ser levadas para as aulas de Educação Física, a fim de se promover o conhecimento e a vivência sobre este esporte a todos os 
Dossiê | A iniciação esportiva no esporte paralímpico: o caso do voleibol sentado (SANCHOTENE, Vitória Crivellaro; BATAGLION, Giandra Anceski; MAZO, Janice Zarpellon)

alunos, não somente àqueles com deficiência. E, ainda que a turma não possua alunos com deficiência, o desenvolvimento de modalidades paralímpicas se faz pertinente, pois desperta o olhar e a sensibilização/conscientização para a diversidade, contribuindo para o educar de todos(as).

Neste estudo, notou-se que embora nem todas as atletas tenham desfrutado de experiências positivas nas aulas de Educação Física, em período em que quatro delas ainda não havia adquirido a deficiência, seus percursos convergiram para a inserção no esporte paralímpico, dadas as motivações e intenções particulares de indivíduos e entidades ligadas a este universo que conferiram a elas tais oportunidades. Com todo o caminho percorrido e com as conquistas, pessoais e profissionais, alcançadas na carreira paralímpica, as cinco atletas entrevistadas corroboraram sobre o papel da Educação Física escolar para se favorecer e potencializar o processo de iniciação esportiva, em especial, no esporte paralímpico.

Oportunizar o conhecimento sobre as distintas possibilidades de engajamento em práticas corporais, atividades físicas ou esporte, sejam estas adaptadas ou não, é um direto de todos(as), sejam pessoas com ou sem deficiência. Isto promove a aderência aos espaços esportivos e a conquista do ser no lugar do estar no meio social. A Educação Física inclusiva é um espaço que congrega todas estas oportunidades, sendo lócus para a construção de seres humanos conscientes e despidos de preconceitos sobre a diversidade humana, seja na escola ou fora dela.

\section{Considerações Finais}

Este estudo investigou como ocorreu a inserção de atletas da seleção brasileira feminina de voleibol sentado na prática esportiva desta modalidade paralímpica. Evidenciou-se que a deficiência impõe uma necessidade de mudança nos percursos individuais e o esporte paralímpico é um instrumento de direito destas pessoas, facilitando o entendimento da sua condição - de pessoa com deficiência. Após a fase de aceitação e de adaptação com a deficiência, em especial para quem a adquire ao longo da vida, foi possível perceber a ocorrência de sentimentos positivos relacionados ao voleibol sentado nas falas das atletas entrevistadas. Nesse processo, compreendeu-se que o treinador é um propulsor para a fase de iniciação esportiva no esporte 
Dossiê | A iniciação esportiva no esporte paralímpico: o caso do voleibol sentado (SANCHOTENE, Vitória Crivellaro; BATAGLION, Giandra Anceski; MAZO, Janice Zarpellon)

paralímpico. Através dos relatos notou-se que a Educação Física escolar pode ser uma ferramenta para contribuir nos momentos iniciais da carreira da atleta no esporte paralímpicos. De semelhante importância, entidades de saúde e seus profissionais desempenham papel primordial com o encaminhamento da pessoa com deficiência para a prática de modalidades paralímpicas.

Estudos com o viés de difundir a iniciação esportiva em esporte paralímpico contribuem para estimular o início da prática, visando futuros recursos humanos, bem como o conhecimento da população acerca das questões ligadas ao esporte para pessoas com deficiência. Verifica-se que a aproximação com a modalidade gerou benefícios ao crescimento pessoal de algumas atletas. Assim como o contato com outras pessoas com deficiência as fizeram perceber em si potencialidades que antes não eram cogitadas.

Os resultados deste estudo possuem intensas relações com o contexto do esporte paralímpico brasileiro na década de 2000, pois quatro das cinco atletas entrevistadas ingressaram no voleibol sentado neste período - uma delas iniciou em 2011. Ademais, os anos 2000 marcaram os primórdios da prática institucionalizada desta modalidade no Brasil e as primeiras participações da seleção brasileira feminina em campeonatos internacionais. Vale mencionar que houve tentativa de participação desta seleção nos Jogos Paralímpicos de 2008, realizados em Pequim (China), contudo esta ideia não foi concretizada devido à ausência de conquistas na etapa classificatória - o Campeonato Mundial da Modalidade. Após um ciclo paralímpico, as mulheres da seleção brasileira feminina de voleibol sentado realizaram este sonho, representando o país na modalidade pela primeira vez, nos Jogos Paralímpicos de 2012, em Londres, na Inglaterra. Hoje, após quase duas décadas da institucionalização do voleibol sentado feminino no Brasil, novas pesquisas sobre as formas de iniciação das atletas nesta modalidade poderiam trazer resultados distintos dos apresentados neste estudo, denotando particularidades relativas ao novo período histórico do esporte paralímpico brasileiro, o qual, atualmente, é considerado potência mundial. 
Dossiê | A iniciação esportiva no esporte paralímpico: o caso do voleibol sentado (SANCHOTENE, Vitória Crivellaro; BATAGLION, Giandra Anceski; MAZO, Janice Zarpellon)

\section{Referências}

BATAGLION, Giandra Anceski; MAZO, Janice Zarpellon. Paralimpíadas Escolares (2006-2018): Evidências em mídias digitais acerca do evento esportivo. Recorde - Revista de História do Esporte, Rio de Janeiro/RJ, v. 12, n. 1, p. 1-42, 2019a.

BATAGLION, Giandra Anceski; MAZO, Janice Zarpellon. Paralimpíadas Escolares: representações sociais acerca do esporte paralímpico no Rio Grande do Sul. Revista de Educação da Universidade Federal do Vale do São Francisco - REVASF, Petrolina/PE, v. 9, n. 19, p. 353-385, 2019b.

BATAGLION, Giandra Anceski; MAZO, Janice Zarpellon. Legados das Paralimpíadas Escolares para o Esporte Paralímpico no Brasil. Revista Eletrônica do Programa de PósGraduação da Câmara dos Deputados, Brasília/DF, v. 12, n. Especial: Políticas e Pesquisas sobre Esporte, p. 24-47, 2019c.

BATAGLION, Giandra Anceski; MAZO, Janice Zarpellon; BEGOSSI, Tuany Defaveri; $\mathrm{HAICHI}$, Marcelo de Castro. A social representation of the disabled person in the paralympic universe: from studens to athlets. In: OLIVEIRA, Ailton Fernando Santana de; HAIACHI, Marcelo de Castro (orgs.). The future of the olympic and paralympic games 5th Debate Cycle in Olympic and Paralympic Studies. 1 ed. Florianópolis: Tribo da Ilha, v. 1, 2019, p. 195-223.

BEGOSSI, Tuany Defaveri; MAZO, Janice Zarpellon. O percurso das mulheres pioneiras no cenário paralímpico Sul-rio-grandense. Revista Brasileira de Ciência e Movimento, Brasília/DF, v. 24, n. 4, p. 143-155, 2016.

BELTRAME, André Luís Normanton; SAMPAIO, Tânia Mara Vieira. Atendimento especializado em esporte adaptado: discutindo a iniciação esportiva sob a ótica da inclusão. Revista da Educação Física/UEM, [s.I.], v. 26, n. 3, p.377-388, 12 ago. 2015. Universidade Estadual de Maringa. http://dx.doi.org/10.4025/reveducfis.v26i3.24990.

BENFICA, Dalila Tâmara. Esporte paralímpico: analisando suas contribuições nas (re)significações do atleta com deficiência. 2012. 115f. Sc. Universidade Federal de Viçosa, abril de 2012.

BERTOLDI, Rafaela; et al. Esporte Paralímpico e possíveis fatores determinantes do desempenho esportivo: estudo de caso. Motricidade, Portugal, v. 14, n. S1, p. 254262, 2018.

BRASIL. Decreto Legislativo no 186, de 09 de julho de 2008. Decreto no 6.949, de 25 de agosto de 2009. Convenção sobre os Direitos das Pessoas com Deficiência. 4a Ed., rev. e atual. Brasília, Secretaria de Direitos Humanos, p. 100, 2011.

BRASIL, Lei no10.264, de 16 de julho de 2001. Lei Agnelo/Piva. Disponível em: http://www.planalto.gov.br/ccivil_03/Leis/LEIS_2001/L10264.htm. Acesso em 10/06/2018.

BRASIL. Lei no 13146, de 06 de julho de 2015. Institui a Lei Brasileira de Inclusão da Pessoa Com Deficiência (Estatuto da Pessoa com Deficiência). Disponível em: 
Dossiê | A iniciação esportiva no esporte paralímpico: o caso do voleibol sentado (SANCHOTENE, Vitória Crivellaro; BATAGLION, Giandra Anceski; MAZO, Janice Zarpellon)

http://www.planalto.gov.br/CCIVIL 03/ Ato2015-2018/2015/Lei/L13146.htm. Acesso em: 10 de junho de 2019.

CARDOSO, Vinícius Denardin. O desenvolvimento da carreira esportiva de atletas paraolímpicos no Brasil. 2016. 217 f. Tese (Doutorado em Ciências do Movimento Humano) - Escola de Educação Física, Fisioterapia e Dança, Universidade Federal do Rio Grande do Sul, Porto Alegre, 2016.

CARDOSO, Vinícius Denardin et al. A contribuição da mídia na construção dos ídolos paralímpicos brasileiros. Brazilian Journal of Education, Technology and Society. [S.I.], v. 11, n. 1, p.78-86, 31 mar. 2018. Disponível em: http://brajets.com/index.php/brajets/article/view/471/245. Acesso em: 25 de setembro de 2018.

CARDOSO, Vinícius Denardin et al. Esporte paraolímpico no Brasil: de sua estruturação a sua consolidação. Revista Portuguesa de Ciências do Desporto, Porto, v. 1, n. 16, p.59-72, 2017.

CARVALHO, Camila Lopes; GORLA, José Irineu; ARAÚJO, Paulo Ferreira de. Voleibol Sentado: do conhecimento à iniciação da prática. Conexões: Revista da Faculdade de Educação Física da Unicamp, Campinas, v. 11, n. 2, p.97-126, abr./jun. 2013.

CONDE, Antonio João Manescal; SOBRINHO, Pedro Américo de Souza; SENATORE, Vanilton. Manual de Orientação para os Professores de Educação Física: introdução ao Movimento Paraolímpico. Brasília/DF: Comitê Paraolímpico Brasileiro, 2006, 1CD-ROM. CONDE, António João Menescal. Memória Paralímpica. São Paulo: Comitê Paralímpico Brasileiro, 2018.

CRESWELL, John W. Projeto de Pesquisa: Métodos qualitativo, quantitativo e misto. 3. ed. Porto Alegre: Artmed, 2010. 296 p.

DANTAS, José Agtônio Guedes. Ciclo de debates em estudos Olímpicos e Paraolímpicos. Os desafios do voleibol sentado feminino para os Jogos do Rio 2016. Organização: OLIVEIRA, Ailton Fernando Santana de; HAIACHI, Marcelo de Castro. Diferentes olhares dos Jogos Rio 2016: a mídia, os profissionais e os espectadores. Aracaju: Diário Oficial do Estado de Sergipe, 2018. p. 1-378.

FERNANDES, Flávia de Camargo. O esporte para pessoa com deficiência física: da iniciação esportiva à prática regular. 2019. 1 recurso online (104p.). Dissertação (mestrado) - Universidade Estadual de Campinas, Faculdade de Educação Física, Campinas, SP.

FERREIRA, Eliana Lucia (Organizadora). Esportes e atividades físicas inclusivas. v. 5. Niterói: Intertexto, 2014.

GORLA, José Irineu; CALEGARI, Décio Roberto. O esporte como ferramenta de reconhecimento e valorização da pessoa com deficiência no Brasil. Conexões: Educação Física, Esporte e Saúde, Campinas/SP, v. 15, n. 2, p. 257-270, abr./jun., 2017.

GREGUOL, Márcia; COSTA, Roberto Fernandes da (Organizadores). Atividade Física Adaptada: qualidade de vida para pessoas com necessidades especiais. 4 ed. Barueri/SP: Manole, 2019. 
Dossiê | A iniciação esportiva no esporte paralímpico: o caso do voleibol sentado (SANCHOTENE, Vitória Crivellaro; BATAGLION, Giandra Anceski; MAZO, Janice Zarpellon)

HAIACHI, Marcelo de Castro. O curso de vida do atleta com deficiência: a deficiência e o esporte como eventos marcantes. 2017. 240 f. Tese (Doutorado em Ciências do Movimento Humano). Escola de Educação Física, Fisioterapia e Dança, Universidade Federal do Rio Grande do Sul, Porto Alegre, 2017.

HAIACHI, Marcelo de Castro et al. Reflexões sobre a carreira do atleta paraolímpico brasileiro. Ciência \& Saúde Coletiva, Rio de Janeiro, v. 21, n. 10, p.29993006 , out. 2016.

Disponível

em:

http://www.scielo.br/scielo.php?script=sci arttext\&pid=S1413-

81232016001002999\&lng=pt\&tIng=pt. Acesso em: 07/05/2018.

IBGE. População residente por tipo de deficiência permanente. 2010. Disponível em:

https://biblioteca.ibge.gov.br/visualizacao/periodicos/94/cd_2010_religiao_deficienci a.pdf. Acesso em: 20 mar. 2020.

INTERNATIONAL PARALYMPIC COMMITTEE. Classification: Fair and equal competition. 2015. Official Website of the Paralympic Movement. Disponível em: https://www.paralympic.org/classification. Acesso em: 30 jun. 2019.

INTERNATIONAL PARALYMPIC COMMITTEE. (2019). What are the Paralympic values?. Disponível em: https://www.paralympic.org/feature/what-are-paralympicvalues. Acesso em: 05 abr. 2020.

PALACIOS, Jenica María Herrera et al. Fisioterapia y balance en deportistas de voleibol sentado en la Selección Colombia de Voleibol Sentado rama masculina. Revista Cubana de Investigaciones Biomédicas, Ciudad de La Habana, v. 4, n. 33, p.344-354, set. 2014.

REIS, Rafael Estevam; MEZZADRI, Fernando Marinho; SILVA, Marcelo Moraes e. As políticas públicas para o esporte paralímpico no Brasil: apontamentos gerais. Revista Corpoconsciência, Cuiabá. v. 21, n. 1, p. 58-69, jan. 2017.

RESENDE, Mariana Corrêa de. Análise do perfil psicológico de participantes brasileiros de paradesporto em nível escolar: motivação e resiliência. 2018. $96 \mathrm{f}$. Dissertação (Mestrado) - Universidade Federal de São João Del Rei, Programa de Mestrado em Psicologia, São João Del Rei, 2018.

SANCHOTENE, Vitória Crivellaro. Percursos e memórias esportivas das atletas da seleção brasileira feminina de voleibol sentado. 2019. 90 f. Dissertação (Mestrado) Curso de Educação Física, Universidade Federal do Rio Grande do Sul, Porto Alegre, 2019.

VICCARI, Gabriely Souza; MATTES, Verônica Volski. Construções e transições de carreira no esporte adaptado: um estudo de caso com uma atleta paralímpica da seleção brasileira do voleibol sentado. Revista da Sobama, Marília, v. 19, n. 2, p. 89102, dez., 2018.

WINNICK, Joseph P. Adapted physical education and sport. 5th edition. Human Kinetics, 2010. 